Florida International University FIU Digital Commons

2001

\title{
Apollo and Daphne : an analysis of the work composed by Kari Henrik Juusela
}

Amy Dickinson

Florida International University

DOI: $10.25148 /$ etd.FI14062284

Follow this and additional works at: https://digitalcommons.fiu.edu/etd

\section{Recommended Citation}

Dickinson, Amy, "Apollo and Daphne : an analysis of the work composed by Kari Henrik Juusela" (2001). FIU Electronic Theses and Dissertations. 2812.

https://digitalcommons.fiu.edu/etd/2812 
FLORIDA INTERNATIONAL UNIVERSITY

Miami, Florida

APOLLO AND DAPHNE

An Analysis of the Work Composed by Kari Henrik Juusela

A thesis submitted in partial fulfillment of the requirements for the degree of

MASTER OF MUSIC

in

PEREORMANCE

by

Amy Diane Dickinson

Spring 2001 
Acknowledgements

I would like to thank first and foremost Kari Juusela for this wonderful, work of art he has created and his unabounding helpfulness in answering any and all of my questions. Secondly I would like to thank two cello teachers, David Bjella, my former undergraduate professor, and my current teacher, Keith Robinson, for their help and guidance in preparing the work. I would also like to acknowledge Dr. Orlando Garcia for all of his patience, time and effort in helping me to compose and complete this thesis. And lastly, I would like to thank all the people I dragged into a room and made listen to me play Apollo and Daphne fifty thousand times. Thanks! 


\section{APOLLO AND DAPHNE}

An Analysis of the Work Composed by Kari Henrik Juusela

By

Amy Dickinson

Florida International University, 2001 Miami, Elorida

Professor Keith Robinson, Major Professor

The purpose of this thesis is to provide an analytical review of the piece Apollo and Daphne, by Dr. Kari Henrik Juusela. The format for this particular analysis is in nine parts and results are listed within the thesis. It is my conclusion that the work is a wonderful composition, and is a prime example as to how a compilation of new and old music styles work well with one another. 
CHAPTER

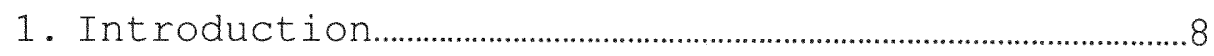

2. Historical Background................................................................. 12

3. Overview, Structure, Texture................................................15

4. Orchestration Techniques..........................................................19

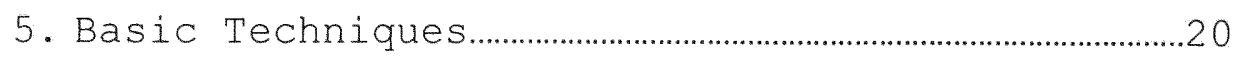

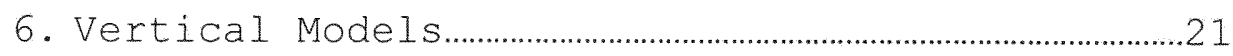

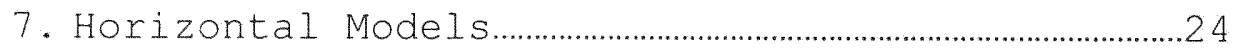

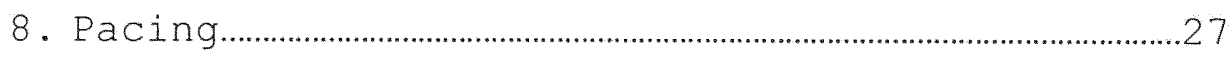

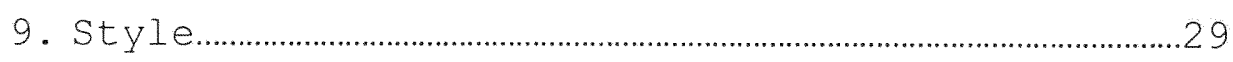

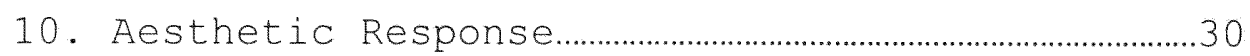

11. Bibliography 
Apollo and Daphne is a famous legend in Greek Mythology that became famous with the help of such artists as Gianlorenzo Bernini and John William Waterhouse through their sculptures and paintings. The legend is based on these two main characters, Apollo and Daphne and details a rather melancholy love story. A shortened version of the legend is as follows:

Daphne was one of the most famous loves of Apollo. She was the daughter of a river, and she had decided to remain unmarried.

One day, Apollo saw Eros playing with his arrows and said, "Little boy, what are you doing with a man's arrows? Leave the archery to me, and be content with your own play things!"

"Apollo, you don't scare me. My arrows are more powerful than yours, and even your medicines can not heal the wounds they cause," Eros replied, taking two arrows from his quiver. One arrow of love, and the other of dislike. He struck Apollo with the arrow of love, and struck Daphne, who happened to be near by with the arrow that will repel it. Instantly, Apollo fell in love with Daphne and was determined to woo her. But Daphne did not want Apollo's love, and ran away from him.

"Daphne my love," Apollo said, running after her. "Do you not recognize me? I am the God of Light, the song, the lyre, and many others! Do not tell me that you do not know me! I am also the God of the oracle of Delphi, I will tell you your future!" But although Apollo offered to show Daphne her future, he did not look into his own. Still, with many words said and done, and 
many miles run between the two, Daphne still refused Apollo, and ran away.

Einally, Daphne was beginning to grow tired, and still, Apollo was running after her. She prayed to her father to protect her from Apollo. Daphne's arms began turning into tree limbs, her body hardened and turned stiff. Her face turned to wood while her hair turned green, and her feet sank into the ground to become roots. When Apollo reached her, he found a tree in her place. She had become a laurel tree. Apollo took her leaves and made it into a wreath. That wreath was then awarded to all victors at olympic games as the highest honor possible. ${ }^{1}$

Dr. Kari Juusela, a composition professor at Stetson University in DeLand, Elorida, evolved this story into a one-movement work for solo cello. It is this work that I will be examining using a slightly modified version of analytical system devised by David Cope. ${ }^{2}$ The system is referred to as a vectoral analysis, the formal definition of this being a quantity with both force and direction; Three-dimensional analytical technique (rather than two dimensional formal or one dimensional harmonic analysis). This slightly modified version has grown to contain all of the following aspects of analysis;

1. Historical Background: (a)Dates of composition; (b) Period of composition; (c) Compositional school if

\footnotetext{
${ }^{1}$ http://library.thinkquest.org/23057/six/apollodaphne.html, 3/20/01@12:30p.m.

2 Modified version as studied and reviewed from Analytical Techniques, a theory course necessary for all graduate music majors at Florida International University.
} 
applicable; (d) country of origin of composer;

(e) Historical influences; (f) Composers teachers;

2. Overview, Structure, Texture, (Eormal Analysis):

Composite structure (homophonic, monophonic,

contrapuntal); (b) Notation and its importance to structure; (c) Rhythmic ideas related to structure; (d) Compositional techniques influencing structure; (e) text(s) if applicable.

3. Orchestration techniques (if applicable): (a)Timbre analysis; (b) Instrumentation; (c) Extended instrumental techniques; (d) Ranges utilized (extreme vs. idiomatic etc.); (e) Unusual balances (e.g. inverted structures); (f) Relation of timbre to form and structure.

4. Basic techniques: (a) Pitch organization; (b) Motivic structures; (c) Rhythmic detail (relative to a and b)

5. Vertical models: (a)Chords/sonorities; (b)Voice leading

6. Horizontal models: (a) Melodic structures;

Cadences; (c) Balance; (d) Direction

7. Pacing: (a) Teleology; (b) Stasis vs. Directionality

8. Style: (a) Summary of stylistic parameters employed by the composer 
9. Aesthetic response: (a) What makes the work "good" or "bad". 3 In the following chapters I will examine all of these aspects in the analysis of Apollo and Daphne.

\footnotetext{
${ }^{3}$ Cope, New Directions in Music, modified by Orlando Garcia
} 
Chapter One: Historical Background

Apollo and Daphne was composed during the summer of 1986. Dr Juusela states though, that the piece was actually thoroughly composed in his head during a trip to Europe in 1981 during which he saw a sculpture of the legend created by Gianlorenzo Bernini.

Dr. Kari Henrik Juusela was born in Espoo, Finland on September 15, 1954. The musical inspiration that lead him to become a composer passed down from his parents, Oiva and Kaija Juusela, who were both performers. Dr. Juusela states,

"I was convinced by my musician parents (mother an opera singer and father a pianist) that Sibelius (the famous Finnish composer) was one step from being a god. I started composing at around four when I composed Suomen Suru Laulu (Finland's Sad Song) which my mother notated for me. Other early inspirations were Ginastera, Stravinsky, Mozart, Jimi Hendrix, Frank Zappa, and The Art Ensemble of Chicago." ${ }^{4}$

Dr. Juusela has heavily relied upon the folk music of Finland in his earlier works and later came to appreciate the work of composers such as Einojuhani Rautavaara, Alfred Schnitke, and Louis Andriessen. Dr Juusela also has a deep appreciation, "the mystical connection from Scriabin, Vogel, Rautavaara, etc. Music is mystical and magical to

\footnotetext{
${ }^{4}$ Interview with Kari Juusela, January 10,2001@10:00 a.m.
} 
me." ${ }^{5}$ Other cultural influences rely heavily on American free improvisation which he learned, "growing up in the late $60^{\prime} \mathrm{s}$ in the U.S." 6 Dr. Juusela came to the United States where he earned his degrees from Berklee college of Music, Georgia State University, and University of Maryland respectively. During that time he studied with Mark Wilson, Tom Delio, Charles Knox, T.J. Anderson and Jeronimus Kascinkas, and received training in African music with Komla Amoaku, Indonesian music with Louis Peterman, and Indian music with Nandkishor Muley and Rusty Gillete. Dr. Juusela in now currently on staff at stetson University where he holds the position of Associate Dean and Director of Composition.

Upon asking the composer what compositional school he would place the piece he was at first unsure but definelty views the style as "sort of a mid to late $20^{\text {th }}$ century nationalistic Finnish folk influenced style."7 He goes on to say that the music is influenced by rustic Karelian Einnish folk music which features an abundance of mixed

\footnotetext{
${ }^{5}$ lbid

${ }^{6}$ lbid

${ }^{7}$ lbid
} 
meters and sudden changes from the major mode to minor (and/or modal changes). ${ }^{8}$

${ }^{8}$ Ibid 


\section{Chapter Two: Overview, Structure, Texture}

The basic composite structure of the piece is that of a monophonic ternary ABA form. Though there is an extended use of chords in the piece, I do not believe this to be an accompanimental aspect of the cello. However, in the introduction of the vivace the chords act in almost a contrapuntal manner. Dr. Juusela used the abundance many chords and sixths to simply get a richer sound using just a solo instrument. He does however considered the piece to,"split into compound melody at certain points".9 The sixths are easier to perform than many other chordal combinations and the chords bring out the sound and harmony while using the unique capabilities of the instrument.

The majority of the notation is based in the lower register of the cello which Dr. Juusela did to, "provide a rustic folksy character. Lower positions accommodate this and I think the instrument has a fuller sound in the lower positions." 10

David Cope suggests in his book Techniques of the Contemporary Composer; "Meter changes and composite meters are two of the most obvious methods of avoiding the

\footnotetext{
${ }^{9}$ Interview with Juusela via Email, Friday, April 6, $2001 @ 7: 43$ a.m.

${ }^{10} \mathrm{Ibid}$
} 
regularity imposed by meter."11 Dr. Juusela seems to have taken this thought to heart during the composition of this work. The rhythm used in the music vary from section to section. We are introduced to the piece with a series of harmonics in a triple meter, based in the key of $D$ major. The musical material then changes only slightly with the introduction of a vi chord at a meter change from $3 / 4$ time into $4 / 4$ time.

In the next section, entitled Vivace (tempo marking 160 equals quarter note), we arrive at a cadence and then are reintroduced to the triple meter with a new theme. We stay in this meter (with a few stints into a duple meter) for quite some time. The rhythms alter from the primary part of the theme to the secondary as seen below in example one and two. The first part of the theme being based on a sixteenth and eighth note passage, and the second doubling the value of the rhythms, being based on eighths and quarter notes.

\footnotetext{
"Cope, pg 90
} 

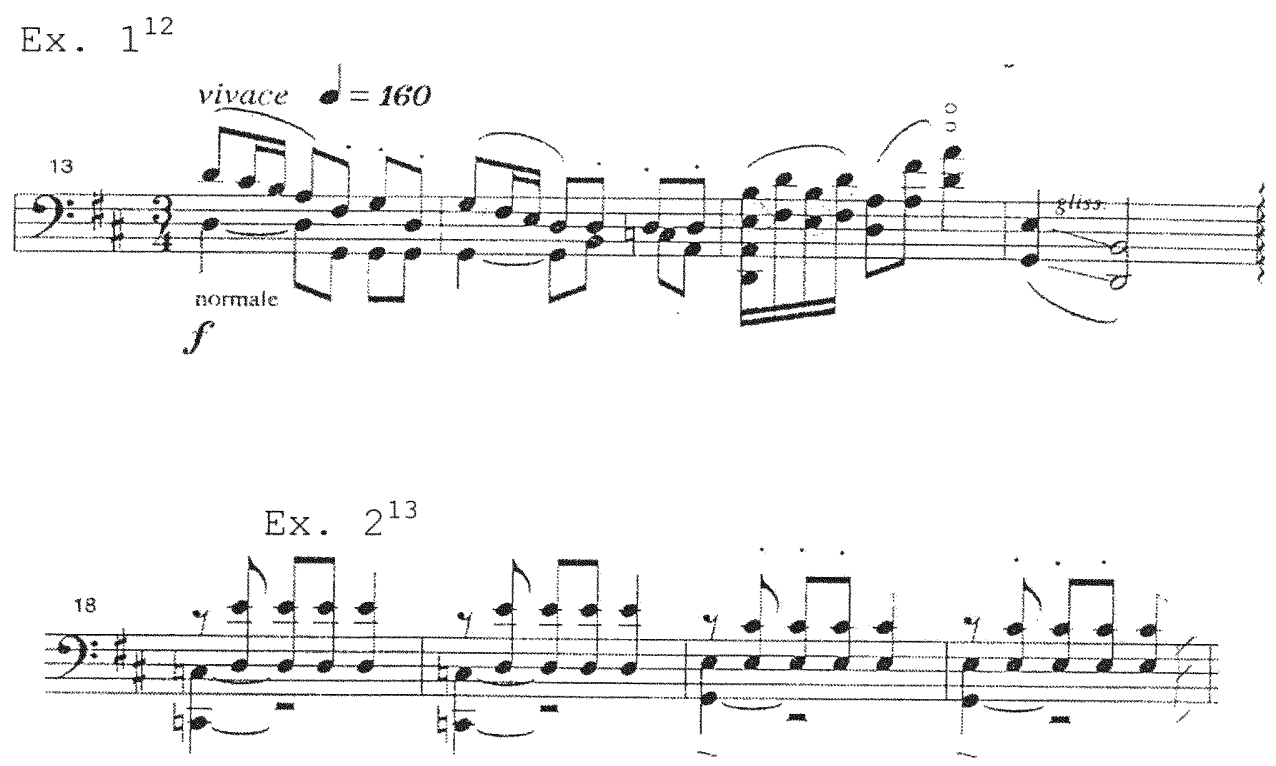

This rhythmic formula in example two, creates the rhythmic doctrine for the rest of the piece. The rhythms are based the eighth note/ sixteenth note capacity with the exception of some triplet turns.

The Vivace section continues on with the same rhythmic basis and it is here we begin to see the introduction of mixed meters mostly for the usage of motivic development. It progresses from 3/4, to $5 / 8$, to $4 / 4$ and then returns to 3/4. The rhythmic development concludes at a cadenza in measure 51 with an introduction to a new motive.

The middle section, or the development of the work, is a bit more sporadic than the introduction. It is divided into three sections, the first two of which last roughly

\footnotetext{
12 Juusela, pg 1

${ }^{13}$ Ibid
} 
six measures. The beginning of this next section, entitled Ianguido, is nearly one-third the tempo of its predecessor at tempo marking 56 equals quarter note. This section continues on utilizing the same eighth-note quarter pattern as seen in the second section of the introduction. Though only six measures in length, this section does change meter from $3 / 4$ to $4 / 4$, but only, once again, to accommodate the motivic development of the line.

The next section is written at nearly double the tempo of the languido at 96 beats per minute. It has the significant difference in that it is the first section in the music to introduce the $7 / 8$ meter. This section only lasts for five measures, but acts as the basis for the melodic material in the upcoming section both melodically and rhythmically.

The final section of the development opens in $7 / 8$ meter at the Vivace tempo we saw in the beginning. This section is the most rhythmically defined section of the work with twenty-eight different meter changes that conclude at the recapitulation. 
The final section of the work is an exact replica of the opening Vivace both thematically and rhythmically in its usage of "Karelian rhythms". ${ }^{14}$

When asked as to what compositional techniques the composer used he had only this to say.

"The piece was first conceived mentally as a reaction to the sculpture. I then sat down and played what I heard on the cello, editing it somewhat. In some sense this is a written out improvisation."15

${ }_{15}^{14}$ Interview with Kari Juusela, January 10, $2001 @ 10: 00$ a.m. ${ }^{15}$ Ibid 
Dr. Juusela's work is relatively traditional in its harmony, form, and even rhythm (if viewed from a motivic development scheme). His harmonic language the majority of the time follows the traditional language of $I, I V, V, I$. The form complies to traditional sonata form of $A B A$, and the rhythmic construction is based on melodic development.

Out of the four extended techniques most commonly found used in music for strings in the $20^{\text {th }}$ century, as defined by David Cope, Dr. Juusela only uses one. His usage of harmonic passages, left hand pizzicati and glissandi fall into the fourth category of combinations and extensions of traditional techniques. ${ }^{16}$

The range of the piece varies from section to section. The usage of the harmonic passage in the opening section of the work creates an almost false impression of the piece having an extreme range. However, the majority of these are found without even leaving the fourth position on the cello. The following sections remain relatively constant with the largest range being a ninth.

${ }^{16}$ Cope, pg. 50 


\section{Chapter Four: Basic Techniques}

I found this piece to be interesting in that the majority of the motivic developments involved chordal support. In fact, only one fifth of the entire piece is not chordal. As stated earlier, it was Dr. Juusela's desire for a rich sound that created the need for such a development. All forms of intervals are utilized but the majority of the chords are organized in sixths, being one of the easiest intervals on the instrument.

The motivic basis of the work seems to center on call and answer. Consequently, the dynamic development of the work mirrors the effect. There are only three sections in the work that do not employ this technique (ms. 12, 25, 57) and these act as harmonic progression or introductions to new thematic material.

Due to the fact that chordal playing does take a good deal more strength, concentration, and effort, I feel it is this reason that even though the piece employs a fast tempo, the rhythms are rarely shorter than that of an eighth note. In fact, there is no section save the opening motive of the vivace, that uses a chord with sixteenth note. 


\section{Chapter Five: Vertical Models}

It is in this section that I harmonically analyze the piece as a whole. Dr. Juusela wrote the piece using traditional tonal/modal writing. ${ }^{17}$ Using a traditional pitch analysis, we can see that the piece is based in the key of D Major. It is not until the twenty-sixth measure that we see some deviation from the key of $D$ to $E$ flat Ionian. After ten measures utilizing this mode the piece gives the impression of moving to the key of d minor, but in actuality, the key is only utilized for two measures keeping us in $E$ flat Ionian. Finally, at the upbrupt conclusion of the first section in E flat Ionian, the piece returns to the opening key of $D$ Major.

The next six measures prepare us for the harmonic progressions we will encounter in the following section. The section gives the impression of being in $\mathrm{D}$ flat Phrygian but could not be considered as such with the absence of $E$ flats. This section quickly changes to D Locrian as we see in the example on the following page.

\footnotetext{
${ }^{17}$ Interview with Kari Juusela, January 10,2001@10:00 a.m.
} 
Ex. $3^{18}$

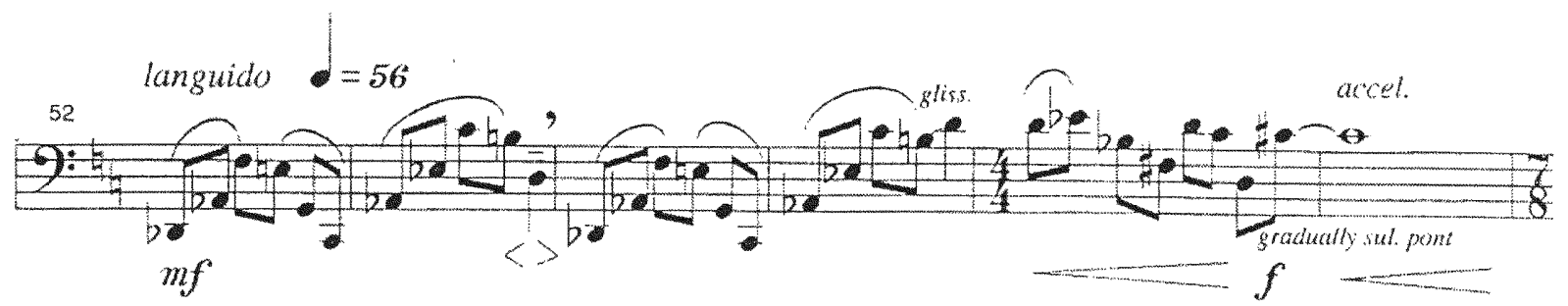

These two modes intertwine within the melody for the next fifty-three measures, but as the piece nears to closing the development, the works tonality modulates us back to D Major. The piece ends with the same material as it commenced with, based in the key of D Major.

The usage of chordal material interesting voice leading in this piece. For example in the beginning, we can see the note d harmonically utilized as a drone. The same goes respectively for the $g$ in the following measure, as seen below in example 1 .

Ex. $1^{19}$

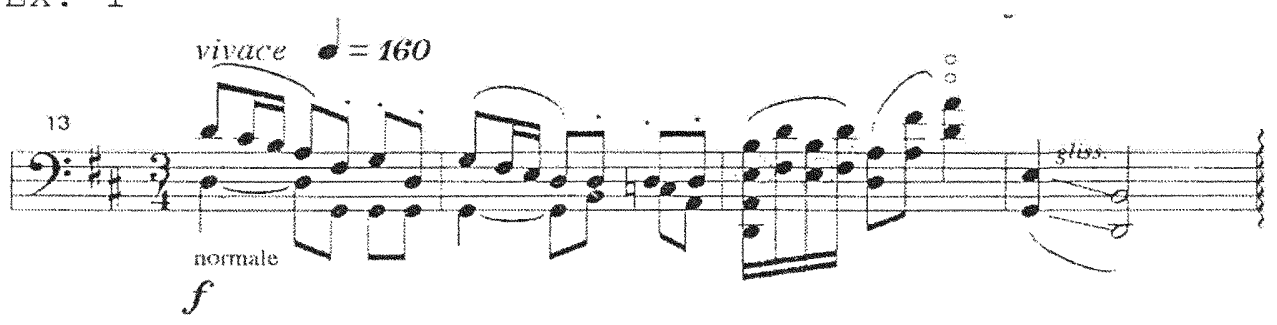

\footnotetext{
${ }_{18}^{18}$ Juusela, pg. 3

${ }^{19}$ Juusela, pg 1
} 
However, these two notes, $d$ and $g$, also create the chordal sonority of the I and IV chords of the key, defining to us exactly what chord is being used. It is in this point that I think that Dr. Juusela strays from the usage of the chords solely for richer material, and starts to think contrapuntally. In this passages it is obvious that some of the chords carry a separate voice and are not used solely for an increase in sound. There are only a few of these passages in the work though, and they are mostly used as introductory material to new themes. The remainder of the chordal progressions are used for the sole purpose of voice doubling with the primary voice being the highest note the majority of the time. 


\section{Chapter Six: Horizontal Models.}

The melodic structure of the piece is in ternary form. This is easy to see due to the fact that the last section of the work consists entirely of the same thematic material as first presented in the Vivace. For each of these sections I will analyze the thematic material from a melodic viewpoint.

The melodic structure of the theme varies constantly throughout the piece. The introductory section can be divided into two lines each of which consist of six measures. In these first two presentations the melodic line seems to follow that of an arc or bell shaped curve and keeps that form until the Vivace. Then, in the Vivace the most important theme of the work is presented to us in the first nine measures as seen below (five of which represent the call, and remainder representing the response).

Ex. $3^{20}$
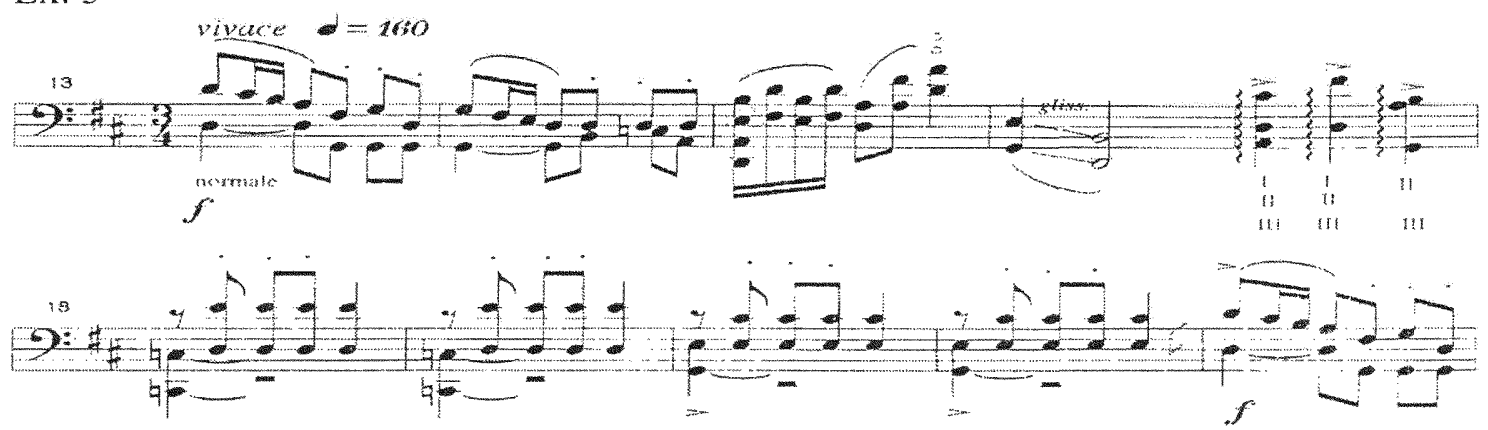

\footnotetext{
${ }^{20}$ Juusela, Pg 1
} 
However, when the call portion of the theme is immediately repeated, the line only consists of four measures as seen in example 4 below.

Ex. $4^{21}$

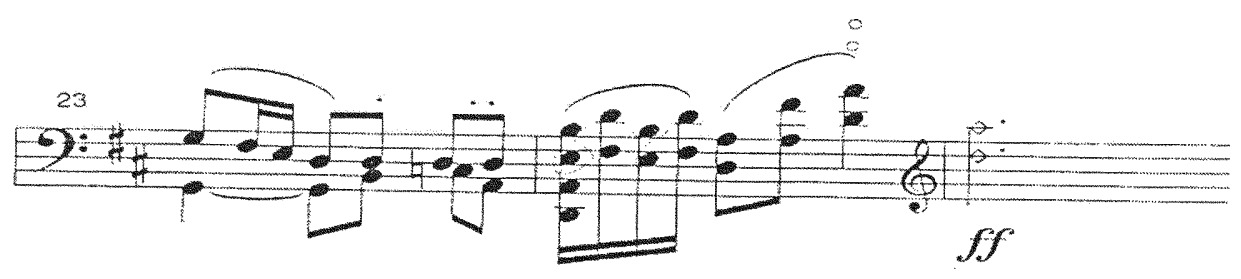

This theme again takes the shape of a bell shaped curve, but in the opposite direction in a falling motion then rising motion. Whereas the piece began in a rising and falling motion, the Vivace does the exact opposite and begins with the high note leading its way down to the lower notes.

If we were just to look at the notes as a straight Iine continuously connected throughout the music, it would be much easier to see the development of the theme, and as to when a new theme is introduced. For example, it is easy to see how in the measure immediately following the conclusion of the restatement of the theme, we are introduced to new thematic material in measure 26. What was once a smooth flowing line, has now formed into a line

${ }^{21}$ Juusela, pg 2 
with several leaps and the introduction of constant sixths. It is also at this point that we leave normal tonal harmony and go strictly in modal harmony until the final section of the work. Even during a short variation of the original thematic material of the Vivace, introduced to us in the minor form in measure 36, we still stay within the realms of E flat Ionian. The movement of the music remains relatively stationary maintaining the leaps and jumps now used, with the slight exception of some falling sixths. This section concludes four measures before the conclusion of the Vivace section with the reintroduction of the main theme.

The next section, languido, mirrors the melodic structure of the beginning with what seems to be introductory material to the next section. The line rises and then falls consistently, and then the next section, entitled tentatively, does the exact opposite with the Iine. This section seems to imitate the opening of the piece with the structure of the line, but in a rather condensed version. The languido section is six measures in length with its introductory statement. The tentatively section is five measures in length with its thematic. statement, apparently with no apparent responsive 
statement. The following thematic line in the Vivace, retains the form of the initial motivic development, with the sections varying in length due to meter and quantity of measures used. The section repeats, and with developmental material (in measures 110-115 with the $d$ and c\# chords) the original motive of the vivace returns.

The cadences in the piece are for the sole purpose of concluding one section of thematic material to introduce us to another. There are no cadences based on any harmonic progressions. The first cadence occurs at the conclusion of the introductory melodic passage. The second cadence occurs the measure previous to the languido, and the final cadence, (not including the final measure of the work) is at the conclusion of the measure previous to the reintroduction of the thematic line of the Vivace. 


\section{Chapter Seven: Pacing}

Teleology is defined as the philosophical study of manifestations of design or purpose in natural processes or occurrences, under the belief that natural processes are not determined by mechanism but rather by their utility in an overall natural design. ${ }^{22}$ The basic concept of this being, do I believe the music to fit its purpose. Since this music is, as Dr. Juusela referred to it, "mildly programmatic"23, I believe the music was designed to fit in this manner. The opening section refers to Apollo resting peacefully when he sees Daphne coming through the woods. The next section, Vivace, is the apparent chase after his true love. The middle section would be Daphne, refusing the advances of her suitor and finally attempting to plea to her father, zeus, to save her from the undying devotion of her suitor. The final section, is once again the pursuit of Daphne, but ends on the harmonics, as Daphne has been transformed into the lovely laurel tree.

Melodic direction, as defined by Cope, is movement toward the point of arrival from the outset, toward the cadence from the point of arrival, and toward continuance

${ }^{22}$ The American Heritage Dictionary of the English Language, pp. 1323

${ }^{23}$ Interview with Kari Juusela, January 10,2001@10:00 a.m. 
from the cadence. ${ }^{24}$ There are, in fact, five necessary elements for a basic melodic concept to occur; flow, points of arrival, cadence, direction, and balance. ${ }^{25}$ The work is modal and therefore composes itself to an almost traditional writing form with clear beginnings and endings. We see this in every section with the introduction of new thematic material and tempo changes, to the cadential formula completing the section, and introducing us to another. The direction of the music is different for each section, some sections progressing upwards in melodic motion, and the others doing the contrary. The line is continual, and maintains the feeling of continuity within the changes of melodic format throughout the work.

${ }^{24}$ Cope, pp. 30 (Techniques of the Modern Composer)

25 Ibid, pp.31 


\section{Chapter Eight: Style}

When asked as to how Dr. Juusela would define the work he defined it as, "Mid to late $20^{\text {th }}$ century nationalistic Finnish folk influenced style." ${ }^{26}$ This is easily apparent due to the folk like nature of the melodic line, the predominant use of modes as opposed to keys, and the rhythms employed in the work. The work is dance-like in nature, yet flows smoothly from a quicker to slower tempo. The dynamics range from piano to double forte and are utilized in a call and answer manner respectively since the majority of the material is repeated twice. Even though the theme is heavily based on traditional folk aspects, the introduction of such extended techniques as harmonics, left hand pizzicati, extreme tempo changes, extreme dynamic contrasts, glissandi, and rapid meter changes show the influence of twentieth century composition.

${ }^{26}$ Ibid 


\section{Chapter Nine: Aesthetic Response}

I have played several of Dr. Juusela's pieces and have always thoroughly enjoyed doing so. The man is capable of composing in all styles of music, but seems to hold his forte in folk music styles as clearly seen in this work.

He consistently touches upon twentieth century techniques, combining the aspects of the old and the new. His musical ingenuity provides a statement of the traditional and the contemporary, educating the average listener to gain an appreciation for both.

Apollo and Daphne is a wonderful work in my opinion. The cello rarely has an opportunity in modern music to display its resonant characteristics. The work is well written for the cello in that Dr. Juusela, being a cellist himself, has a great deal of knowledge about the capabilities of the instrument. It is with the combination of chords, harmonics, and extreme dynamics, that the cello is given the opportunity to, for lack of a better phrase, show off. To state it simply, Dr. Juusela has taken a wonderful piece of music, and combined it with a wonderful instrument. In my mind, the work is and always will be a complete and total success. 
1. Cope, David. New Directions in Music. USA, Wm. C. Brown Company. 1976

2. Cope, David. Techniques of the Contemporary Composer. New York, Prentice Hall International. 1997.

3. Juusela, Kari Henrik. Personal Interview. Subject: Questions for you., kjuuseladstetson.edu, January 10, 2001.

4. Juusela, Kari Henrik. Music Apollo and Daphne, 1986. No publishing company as to date.

5. Morris, William. The American Heritage Dictionary of the English Language, New York, American Heritage Publishing Co.

6. Story or Apollo and Daphne taken from: http://library.thinkquest.org/23057/six/apollodaphne.html,3/20/01@12:30p.m. 
APPENDIX I- Usage of Copyrighted Material of Kari Henrik Juusela 
Date April 13,2001

Kari Henrik Juusela

owner of the copyright to the work known as Apollo and Daphne

hereby authorize Amy Dickinson

to use the following material as part of her thesis to be submitted to Florida International University.

All

I further extend this authorization to University

Microfilms International, Ann Arbor, Michigan, for the

purpose of reproducing and distributing copies of the work.

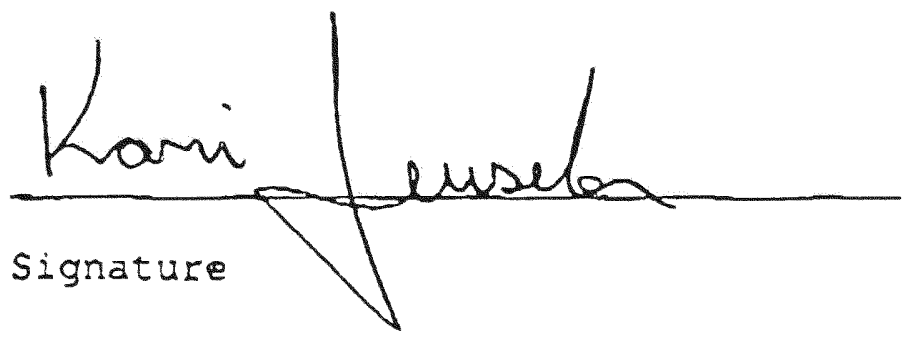

34

TOTAL P.E2

TOTAL P.01 
APPENDIX II- Apollo and Daphne

Kari Henrik Juusela 


\section{Apollo and Daphne \\ for sólo cello}
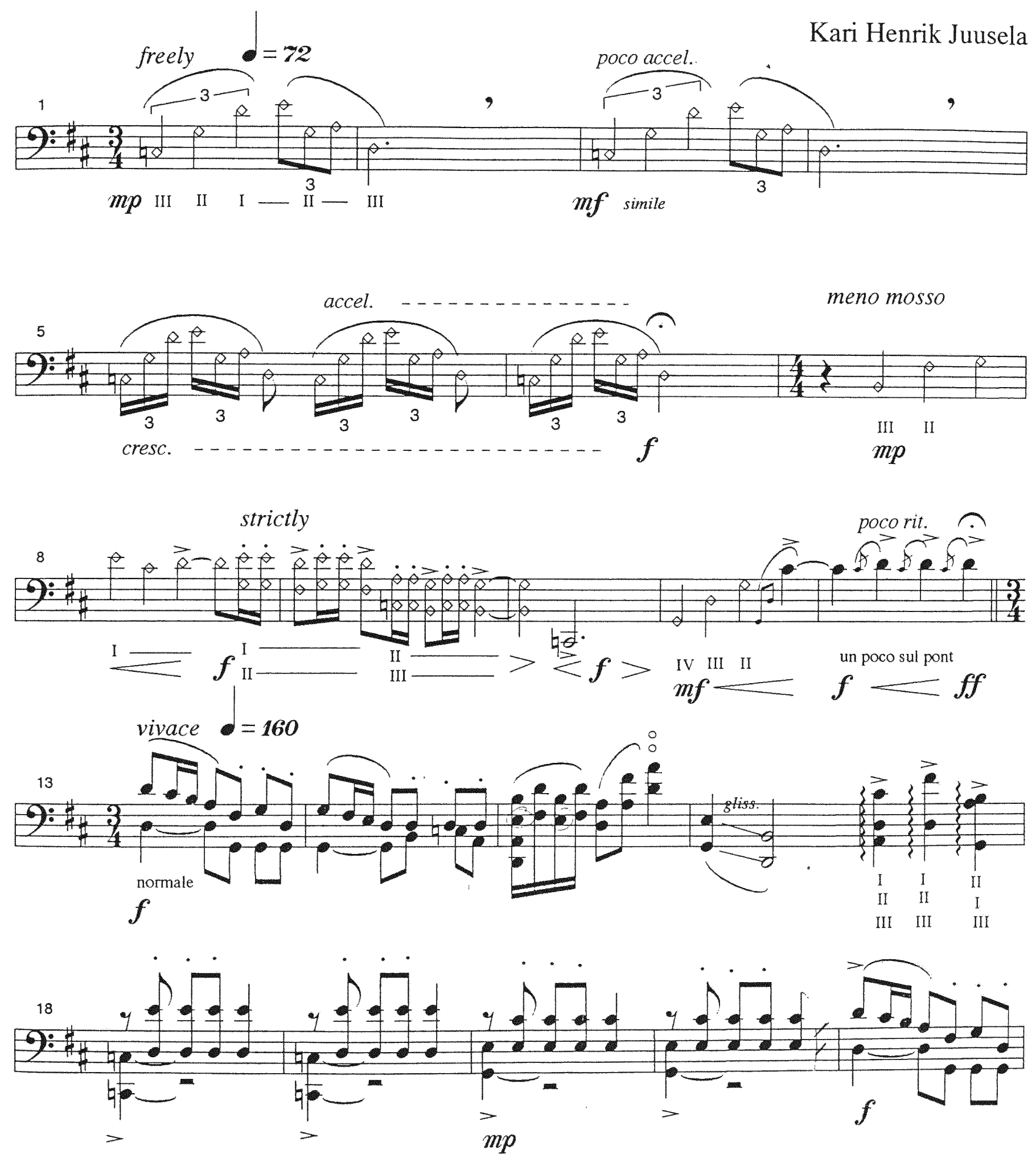

(C) 1987 Kari Henrik Juusela 

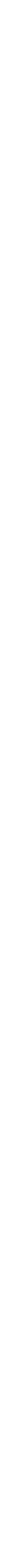


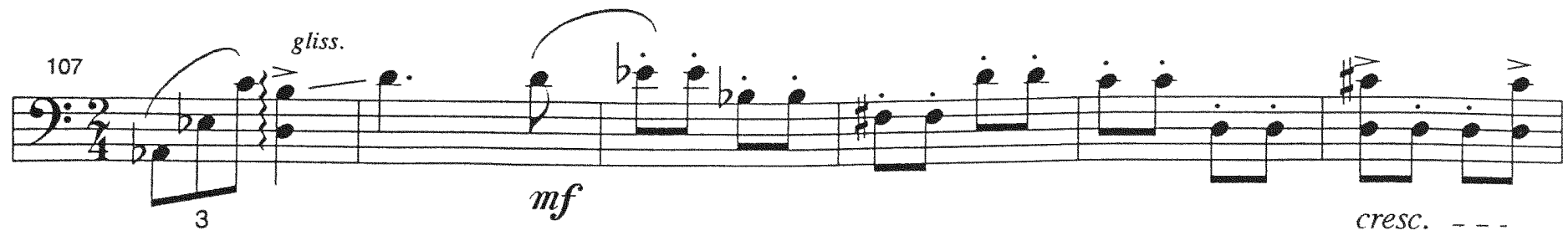

EOC.
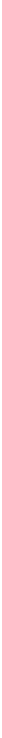